\title{
Study on the problems and Countermeasures of Oil and Gas Storage and Transportation Systems in China
}

\author{
HUA Jinsong ${ }^{1, ~ a, ~ L I ~ H u a i x i n ~}{ }^{2, b}$, LIU Yang ${ }^{3, c}$ \\ ${ }^{1}$ Hebei Tangshan Jidong Oil and gas gathering and transporting company \\ ${ }^{2}$ Jidong Oilfield oil and gas gathering and transporting company \\ ${ }^{3}$ Jidong Oilfield oil and gas gathering and transportation company \\ a Hjs6@sohu.com, ${ }^{\mathrm{b}} \mathrm{Hjs6@sohu.com,}{ }^{\mathrm{C}} \mathrm{Hjs6} @$ sohu.com
}

Keywords: oil and gas storage and transportation systems; safety and environmental protection; Solutions

\begin{abstract}
With the rapid development of Chinese economy, the using amount of both the oil, as an important pillar of industry construction and natural gas, as the energy needed in people's daily lives has been an increasing trend. With the increasing use of oil and gas resources, there are still many problems to be solved in oil and gas storage and transportation processes, for example, oil and gas storage and transportation pipelines are easily corroded, how to prevent fire hazards in oil and gas storage and transportation process, how to reduce evaporation losses by effective means because of its easily evaporating feature in oil gas storage and transportation process, which are the key issues that existing in oil and gas storage and transportation systems needed to attract enough attention. Through in-depth analysis and research to the practical issues, appropriate solutions should be made to ensure the security and environmental protection of oil and gas storage and transportation systems in the oil and gas storage and transportation process.
\end{abstract}

\section{Introduction}

Oil gas resources have provided a steady stream of power to China's economic construction and provided a guarantee to China's economic development. Oil gas storage and transportation systems, as energy utilization hub, have played a significant role in promoting China's economic development. Because China is still in the ranks of the developing countries, related oil gas storage and transportation technology is not advanced, which caused all sorts of problems in the oil and gas storage and transportation process, such as corrosion problems of gas equipment in oil and gas storage and transportation process, fire hazards prevented in oil and gas storage and transportation process and environmental pollution caused by the evaporation loss occurring in the oil and gas storage and transportation process. Therefore, oil gas storage and transportation systems related issues must be valued seriously enough. The in-depth research, propose effective countermeasures to improve the energy efficiency of oil gas, reduce damage to oil and gas storage and transportation equipment and environment pollution play a key role in steady development of our national economic.

\section{Analysis of the Problems in Oil Gas Storage and Transportation Systems}

\section{Fire hazards are prone to happen in oil and gas storage and transportation process}

Oil and gas belong to flammable substances, whose composition is mainly hydrocarbons, and is easy to gather static electricity in the oil and gas storage and transportation process, resulting in fire hazards and even an explosion. Our oil and gas storage and transportation equipment is still relatively backward and poorly designed, whose materials are not standard oil and gas storage and transportation equipment not up to, in the course of operation of the equipment, due to the continued operation of the equipment, the emergence of the phenomenon of high temperature and pressure inside the device, resulting in equipment damage, causing leakage of oil and gas, prone to fire hazards. In the process of oil and gas transportation, oil and gas through pipelines and 
equipment at the time of its friction, piping and equipment due to material non-compliance, prone to static electricity, explosion. Meanwhile, the related operations staff do not follow procedures and ignore safety issues and gas storage and transportation, which are also one of the important reasons for the oil and gas storage and transportation security risk issues.

The evaporation loss problems of oil and gas in storage and transportation process are serious

Mined from oilfield, oil and gas resources are shipped to using enterprise after refined by the refinery through oil gas storage and transportation systems. Oil gas resources utilization process are tedious. In oil gas storage and transportation process, because of the volatile oil and gas, evaporation loss of oil and gas is serious, causing serious waste of resources and great economic losses. Meanwhile, the evaporation of oil gas into the air caused serious environmental pollution. In addition, the mainly used constituent of oil gas in people's production and living is volatile hydrocarbons, whose evaporation and loss direct result in the decline quality of oil gas resources, and lower utilization of oil gas resources.

\section{Gas pipelines and equipment corrosion in oil gas storage and transportation process is} serious

Due to the irrational use of materials, oil gas storage and transportation of equipment and piping in wet hydrogen sulfide environment is prone to corrosion and even crack pipes and equipment. Pipes buried in the ground environmental important is also the main reason leading to corrosion. A variety of reasons, such as underground environment humidity, soil type, underground environment $\mathrm{pH}$ and corrosive substances can cause oil gas transportation pipelines corrosion. In addition, the unreasonable oil gas storage and transportation materials design result in materials to withstand stresses far beyond its yield stress to make device bending and lose its functional role.

\section{Analysis of solution to problems in the process of oil gas storage and transportation}

\section{Pay great attention to fire prevention in oil gas storage and transportation process}

Fire prevention in oil gas storage and transportation process should be started from equipment maintenance and inspection to ensure the safe operation of equipment, control good safety assessment through equipment in oil and gas storage and transportation process. At the same time, optimize the equipment design, introduce advanced technology to upgrade oil gas storage and transportation equipment. To choose equipment materials, you should first consider the material fire resistance, high pressure resistance, explosion-proof and comply with the relevant safety during installation procedures.

And when repair, replace and maintain oil gas storage and transportation equipment, equipment, if needed flare, the device must be moved to a safe work place to avoid fires and result in unnecessary economic losses and casualties.

\section{Do well in piping and equipment anti-corrosion treatment}

Improve the pipe material selection standard. Piping and equipment corrosion cracking occurring is due to cathode stripping or peeling. So in piping and equipment and materials selection, standards for materials must be high and blasting and sanding work in the part where pipes and equipment directly contact with the oil gas must be prepared to deal with, reduce the sulfur content and the amount of hydrogen in the surface of the material to achieve cleanliness and anchor profile of the relevant regulatory requirements. While for welding pipes and equipment, their quality must be qualified, welded junction ensure its rigor to ensure smooth and clean weld pipe inner surface. In order to prevent corrosion of pipes and equipment, a reasonable increase in the thickness of pipe and equipment materials, can effectively prevent stress corrosion and avoid deformation or cracking in piping and equipment.

To reduce oil gas evaporation loss in storage and transportation process

At present, China uses a fixed roof tanks for oil gas transportation, in order to reduce oil gas evaporation losses, transformation of fixed roof tanks is needed, converting it into internal and external floating roof tanks, and arrange professional regularly inspected equipment to ensure its tightness and operation good. Meanwhile, oil and gas recovery measures are also an important way 
to prevent evaporation loss of oil gas. In the process of oil gas canning, set oil gas recovery equipment, through recycling evaporation oil gas in the process of canning to reduce evaporation loss of oil and gas to ensure oil gas quality and reduce the pollution of the environment to achieve efficient use of resources for oil and gas. Finally, strengthening tank tightness is the most direct means. During storage and transportation, oil and gas will get into the atmosphere through the gap between the seal and the tank wall. The better the sealing, the more difficult oil and gas into the atmosphere. Therefore, the sealing effect of the sealing device affects volatilization amount of hydrocarbons. Improving the tank seal is to strengthen double seal of tank seal device. Double seal is composed by a seal and a secondary seal. According to structure, a seal can be divided into three forms, mechanical seal, hydraulic seal and foam seal; the second is to seal tanks using the soft plastic coated on spring board. Strengthening double sealed storage tanks can effectively reduce oil and gas volatilization.

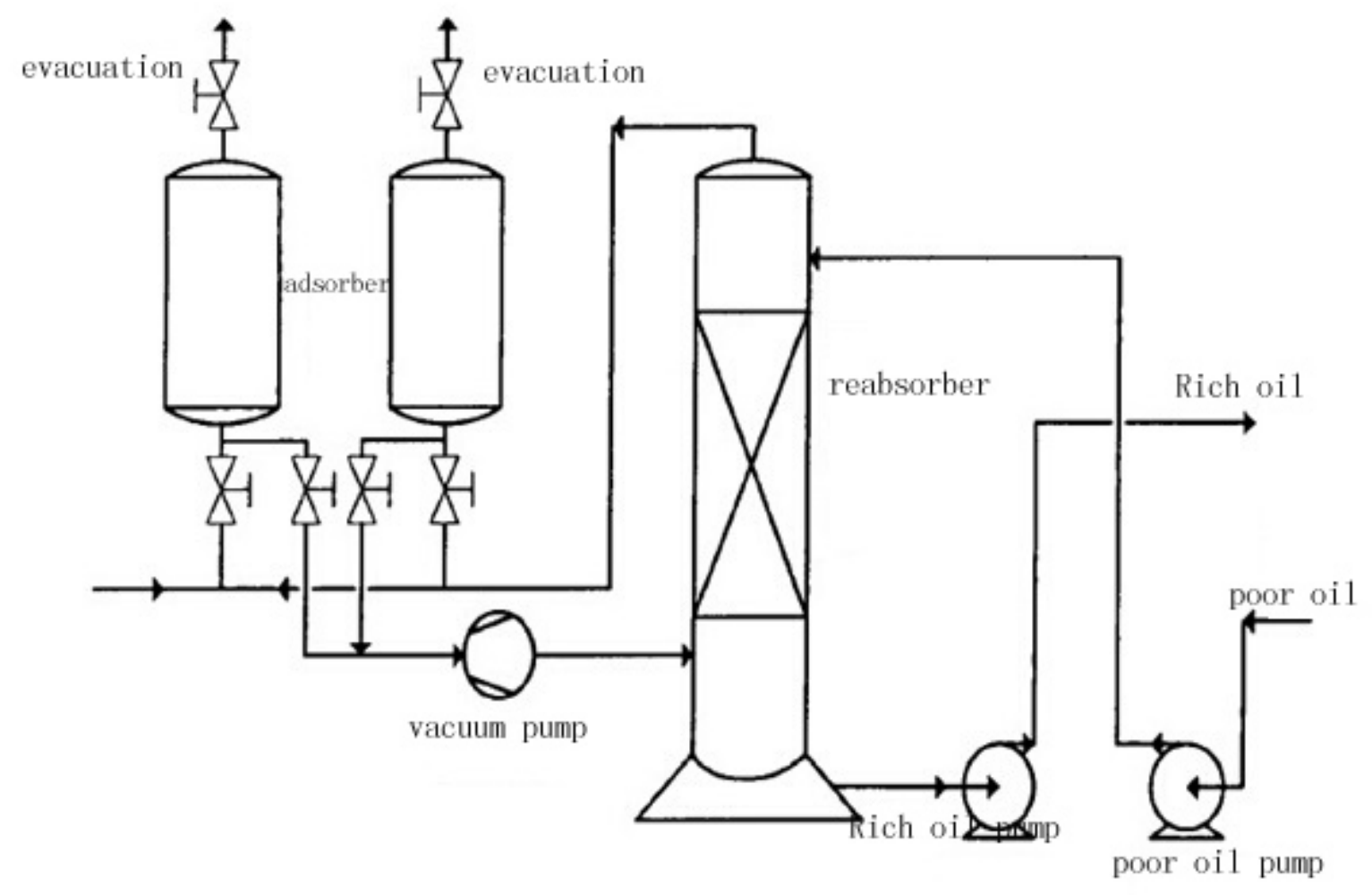

Figure 1 Oil and gas recovery flow chart by adsorption

Adsorption is also an important oil and gas recovery method, whose work is to separate the difficult and the easy adsorption using the the binding force strength difference between each component in the mixture and the adsorbent. Its process consists of four settlement, which includes adsorption, desorption, drying and cooling.

\section{Conclusion}

As a non-renewable resource, petroleum has played a crucial role in China's economic development. Oil and gas storage and transportation hub for the oil industry also played a role on China's industrial construction. Although our oil and gas storage and transportation systems technology is relatively backward and existing problems are still more, as long as full attention is paid to issues related to oil and gas storage and transportation systems, through in-depth research, taking the right formal means to address the oil and gas storage and transportation systems in the various problems, will be able to raise the level of oil gas storage and transportation and promote China's economic development. 


\section{References}

[1] Chen Minjie. The Existing Problem and Countermeasures of Domestic Oil and Gas Storage and Transportation Systems [J]. China Petroleum and Chemical Industry Standards and Quality, 2013,24: 233.

[2]Yu Zhengjiao. Existing Problems and Strategies in the Oil Gas Storage and Transportation Systems [J]. Chinese and foreign entrepreneurs, 2014,02: 203.

[3] Han Gaotian. Security Problems and Countermeasures in the Oil Gas Storage and Transportation [J]. Henan Science and Technology, 2011,12: 62.

[4] Wang Haixiu. Discussion on Problems and Countermeasures in Oil Gas Storage and Transportation Engineering Professional Teaching [J]. Chemical Higher Education, 2011,05: 53-55.

[5] Li Xin. Discussion on problems and countermeasures in oil gas storage and transportation systems [J]. China Petroleum and Chemical Industry standards and quality, 2012,01: 293. 